\title{
Theoretical Studies on the Beam Position Measurement with Button-type Pickups in APS*
}

\author{
Y. Chung
Argonne National Laboratory \\ Y. Chung
Argonne National Laboratory \\ 9700 S. Cass Ave., Argonne, IL 60439
}

ANL/CP--73051

DE91 011998

\section{Abstract}

The response of electrostatic button-type pickups for the measurement of the transverse position of charged particle beams was investigated and analytical formulae were obtained for the signal as a function of time $t$ and the coordinates of the beam and the electrodes. The siudy was done for beam pipes of circular and elliptic cross sections, for rectangular and nonrectangular eleetrodes, and for several cases of longitudinal beam profiles. The numerical results show good agreement with the analytical results, except that the presence of the photon beam channel and the antechamber causes finite offset $(\sim 20 \mu \mathrm{m})$ of the electrical center in the horizontal direction. Time domain analysis indicates that the error in the measurement of the beam position using circular electrodes as compared to rectangular ones was founú to be less than 100 $\mu \mathrm{m}$ per $1 \mathrm{~cm}$ of beam excursion from the center of the beam pipe for the case of APS storage ring vacuum chamber.

\section{INTRODUCTION}

For capacitive pickup devices[1-3], the position of the charged beam is measured through the difference between the electric potentials which develop on the electrodes. For highly relativistic beams, the image charge has the same longitudinal distribution as the beam, due to the Lorentz contraction of the longitudinal component of the electric field.

In this article, we will analyze the response of the button electrodes in both the frequency and the time domains as a function of the transverse position of the beam, taking into account the finite size of the electrodes. The analytical model assumes a simple elliptic geometry for the beam chamber. The results are compared with those obtained numerically for the actual APS beam chamber, and they will be shown to agree quite well. This justifies the use of the analytical model rather than the time-consuming numerical methods to find the optimal position and size of the electrodes and to analyze how the shape of the electrodes affect the beam position measurement.

\section{MONITOR RESPONSE}

Consider an infinitely narrow beam moving along the longitudinal direction with the constant velocity $V$. Following the procedure by Cupcrus[4], instead of solving the full electromagnetic problem directly in the lab frame (unprimed), we will transform to the reference frame (primed) where the beam is at rest, obtain the field and then transform

Work supported by the U.S. Department of Energy. Office of Basic Energy Sciences, under Contract No. W-31-109-ENG-38. back to the lab frame. The electric field $E$ in the lab frame is then, using the Lorentz transformation,

$$
E_{\|}=E_{\|}^{*}, \quad \text { and } \quad E_{\perp}=\gamma E_{\perp} \text {. }
$$

where $y=\left(1-v^{2} / c^{2}\right)^{-1 / 2}$. Thus, the problem is reduced to that of an electrostatic case with linearly distributed charges. [5]

We will first concentrate on the frequency domain, and then discuss the solution in the time domain. Decomposing the electric potential $\Phi^{\prime}(x, t)$ into Fourier components, we writc

$$
\Phi^{\prime}(x, t)=\int d k e^{i k(z-V t)} \Phi^{\prime}\left(x_{1}, k\right),
$$

where the linear dispersion relation $\omega=k V$ was assumed. The integration variable $k$ extends from $-\infty$ to $+\infty$. Then the induced current $I_{p}$ can be expressed as

$$
I_{p}(k)=\dot{r} \operatorname{re}_{0} k V \int d S e^{i k\left(z-z_{l}\right)} \frac{\partial \Phi^{\prime}\left(x_{1}, k\right)}{\partial n}
$$

The integration is done over the area of the electrode surface, and $z_{1}$ is the $z$-coordinate of a reference point, e.g., the center of the electrode $z_{p}$. $n$ is the direction normal to the electrode surface. If the electrode is connected by a coaxial line of characteristic impedance $Z_{0}$ and if the capacitance between the electrode and the beam chamber is $C_{p}$. then the overall impedance $Z_{p}(k)$ for the electrode will be

$$
Z_{p}(k)=\left(\frac{1}{Z_{0}}-i k v c_{p}\right)^{-1}
$$

If ther is frequency filtering represented by $F(k)$, the measured voltage $V_{p}(k)$ will be

$$
V_{p}(k)=Z_{p}(k) I_{p}(k) F(k)
$$

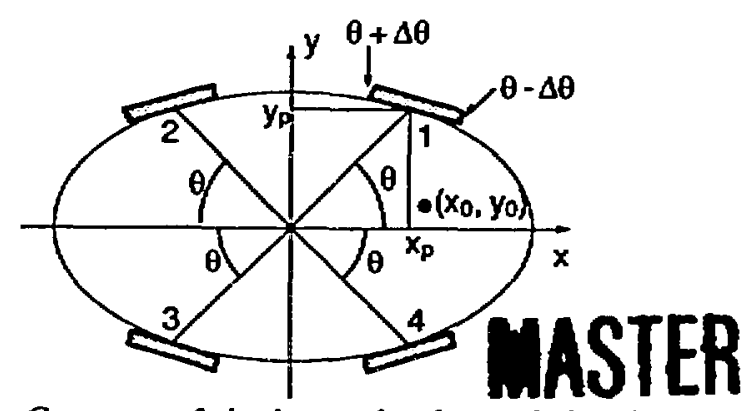

Fig. 1: Geomelry of the beam chamber and the pickup electrodes.
The submitted manuseript has been euthored by a contractor of the U.S. Government under contrect No. W-3t.109-ENG-38. Accordingly, the U.S. Gowernment telairs a nomexclusive. rovelly-free tioente to oublith or reproduce the pubtinhed form of this contribution on allow others to to co, for U. S. Government oumon. 


\section{DISClAMMER}

This report was prepared as an account of work sponsored by an agency of the United States Government. Neither the United States Government nor any agency thereof, nor any of their employees, makes any warranty, express or implied, or assumes any legal liability or responsibility for the sccurncy, completeness, or usefulness of any information, apparatus, product, or process disclowed, or represents that its use would not infringe privately owned rights. Reference herein to any specific commercial product, process, or service by trade name, trademark, manufacturer, or otherwise does not necessarily constitute or imply its eadorsement, reconmendation, or favoring by the United States Government or any ajency thereof. The views and opinions of authors expressed berein do not necossarily state or reflect those of the United States Government or any azency thereof. 
From Eqs. (3) and (5), it suffices to solve the Poisson cquation for the 2-D static potential $\Phi^{\prime}\left(x_{1}, k\right)$ to obtain the electrode response $v_{p}$. The equation is analylically solvable if the beam chamber geometry is somewhat simplified. In this work, elliptic coordinates will be used to approximate the APS beam chamber. We will consider highly relativistic beams only. The current $\mathrm{I}_{\mathrm{b}}$ carried by the beam is represented by

$$
I_{b}(k)=\frac{Q_{b} V D(k)}{2 \pi}, \quad D(0)=1
$$

$Q_{b}$ is the total charge in a single bunch and $D(k)$ is the Fourier transform of the longitudinal charge distribution $\rho(z)$.

Assuming a rectangular electrode flush with the interior surface, the electrode current $\mathrm{J}_{\mathrm{p}}(\mathrm{k})$ can be expressed as

$$
I_{p}(k)=-i \frac{2 \Delta \theta}{\pi} I_{b}(k) \sin k \Delta z G\left(\mu_{0}, \theta_{0}\right) \text {, }
$$

where

$$
G\left(\mu_{0}, \theta_{0}\right)=1+2 \sum_{m=1}^{\infty} \frac{\sin m \Delta \theta}{m \Delta \theta} G_{m}\left(\mu_{0}, \theta_{0}\right),
$$

and

$$
\begin{aligned}
G_{m}\left(\mu_{0}, \theta_{0}\right)= & \frac{\cosh m \mu_{0}}{\cosh m \mu_{p}} \cos m \theta_{0} \cos m \theta_{p}+ \\
& \frac{\sinh m \mu_{0}}{\sinh m \mu_{p}} \sin m \theta_{0} \sin m \theta_{p} .
\end{aligned}
$$

Here, $\Delta \theta$ and $\Delta z$ are half the angular and the longitudinal sizes of the rectangular electrode. The subscripts 0 and $p$ denote the bunch and the electrode, respectively. From Egs. (5) and (7), the coupling impedance $Z_{c}(k)$ can be obtained:

$$
\begin{aligned}
Z_{c}(k) & =\frac{V_{p}(k)}{I_{b}(k)} \\
& =-i \frac{2 \Delta \theta}{\pi} \sin k \Delta z G\left(\mu_{0}, \theta_{0}\right) Z_{p}(k) F(k) .
\end{aligned}
$$

In the time domain, we find from Eq. (5) that $V_{p}(l)$ is separated into the time-dependent and the position-dependent factors for rectangular electrodes as

$$
V_{p}(t)=T(t) P\left(x_{\perp 0}\right)
$$

where

$$
\begin{gathered}
T(t)=\frac{Q_{b} \Delta \theta}{\pi^{2} C_{p}} \int d k \frac{e^{i k\left(z_{1}-V l\right)}}{k+i x} \sin k \Delta z D(k) F(k), \\
\left(\kappa=\frac{1}{Z_{0} V C_{p}}\right)
\end{gathered}
$$

and

$$
P\left(x_{10}\right)=P_{0}\left(x_{10}\right)+\sum_{m=1}^{\infty} \frac{\sin m \Delta \theta}{m \Delta \theta} P_{m}\left(x_{\perp 0}\right) .
$$

For the elliplic case,

$$
P_{m}\left(x_{\perp 0}\right)=\frac{2}{1+\delta_{m 0}} G_{m}\left(\mu_{0}, \theta_{0}\right)
$$

Once the longitudinal charge distribution $\rho(z)$ and the filtering function $F(k)$ are known, it is straightforward to calculate the electrode response $v_{p}(l)$. For certain cases of $\rho(z)$, it is possible to evaluate $v_{p}(t)$ analytically using the residue theorem of complex variables. In the discussion below, we will use the following parameters: $C_{p}=6 \mathrm{pF}, \Delta z=$ $0.5 \mathrm{~cm}, \sigma=1 \mathrm{~cm}, \mathrm{Q}_{\mathrm{b}}=3.5 \mathrm{nC} / \mathrm{mA}$ (single bunch), $\mathrm{x}_{\mathrm{p}}=$ $1.38 \mathrm{~cm}$. Figure 2 shows the clectrode signal $\mathrm{v}_{\mathrm{p}}(\mathfrak{l})$ without frequency filtering. If the electrodes are not rectangular, the results are similar but a bit more complicated. One notable difference is that $V_{p}(t)$ for non-rectangular electrodes is not separable as in Eq. (11).

\section{BEAM POSITION MEASUREMENT}

As shown in Fig. 1, four button-type pickups will be installed for each unit. The quantities $\Delta_{x}, \Delta_{y}$ and $\Sigma$ are defined as follows.

$$
\begin{aligned}
& \Delta_{x}=v_{p l}+v_{p 4}-v_{p 2}-v_{p 3}, \\
& \Delta_{y}=v_{p 1}+v_{p 2}-v_{p 3}-v_{p 4}, \\
& \Sigma=v_{p 1}+v_{p 2}+v_{p 3}+v_{p 4} .
\end{aligned}
$$

The horizontal and the vertical positions of the beam are then determined from

$$
\mathrm{X}_{0}=\frac{\Delta_{\mathrm{x}}}{\Sigma}=\mathrm{S}_{\mathrm{x}} \mathrm{x}_{0}+\mathrm{R}_{\mathrm{x}} \text {, and } \mathrm{Y}_{0}=\frac{\Delta_{\mathrm{y}}}{\Sigma} \approx \mathrm{S}_{\mathrm{y}} \mathrm{y}_{0}+\mathrm{R}_{\mathrm{y}} \text {. }
$$

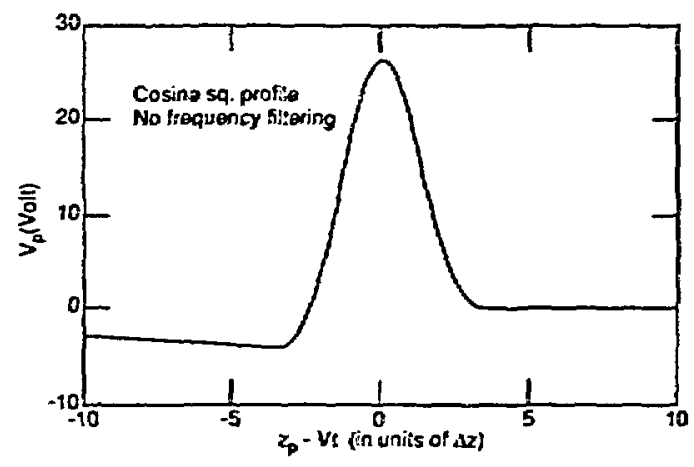

Fig. 2: The elcctrode signal $\mathrm{V}_{\mathrm{p}}$ as a function of time ? without frequency filtering. $z_{p}$ is the clectrode center coordinate and $\Delta z$ is half the longitudinal size. 


\begin{tabular}{|c|c|c|c|}
\cline { 2 - 4 } \multicolumn{1}{c|}{} & $\begin{array}{c}\text { Analytical } \\
\text { result }\end{array}$ & \multicolumn{2}{c|}{$\begin{array}{c}\text { Numerical } \\
\text { result }\end{array}$} \\
\hline yo $(\mathrm{cm})$ & $\mathrm{S}_{\mathrm{x}}\left(\mathrm{cm}^{-1}\right)$ & $\mathbf{S}_{\mathrm{x}}\left(\mathrm{cm}^{-1}\right)$ & $\mathbf{R}_{\mathrm{x}}$ \\
\hline 0.0 & 0.569 & 0.565 & -0.0011 \\
0.2 & 0.580 & 0.576 & -0.0011 \\
0.4 & 0.616 & 0.610 & -0.0011 \\
0.6 & 0.676 & 0.667 & -0.0010 \\
0.8 & 0.763 & 0.747 & -0.0010 \\
1.0 & 0.877 & 0.850 & -0.0009 \\
1.2 & 1.017 & 0.974 & -0.0008 \\
1.4 & 1.178 & 1.113 & -0.0008 \\
\hline
\end{tabular}

T:ble 1: Comparison between the analytical and the numerical results for the $x$ direction. The offset $R_{x}$ for the analytical case is zero.

The linear approximation is valid only when $x_{0}$ and $y_{0}$ are small. $S_{x}$ and $S_{y}$ are the sensitivity functions ard $R_{x}$ and $R_{y}$ are the offset errors. Figure 3 shows $X_{0}$ as a function of the beam position $x_{0}$ for several cases of $y_{0}$, and Fig. 4 shows the contour plotting of both $X_{0}$ and $Y_{0}$. Table 1 lists the sensitivity function $S_{X}$ obtained analytically for the elliptic beam chamber and numerically for the actual APS beam chamber. The two results agree quite well. The finite offset error $R_{x}$ is due to broken symmetry in the $x$-direction due to the presence of the photon beam channel and the antcchamber. The optimal position of the electrodes which gives the same sensitivity in both $x$ and $y$ directions was found to be $x_{p}=$

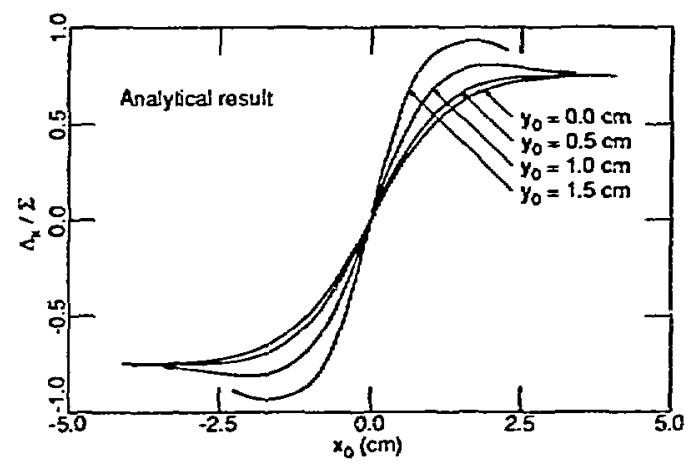

Fig. 3: The ratio $\Delta_{x} / \Sigma$ as a function of the beam position $x_{0}$ for several cases of yo.

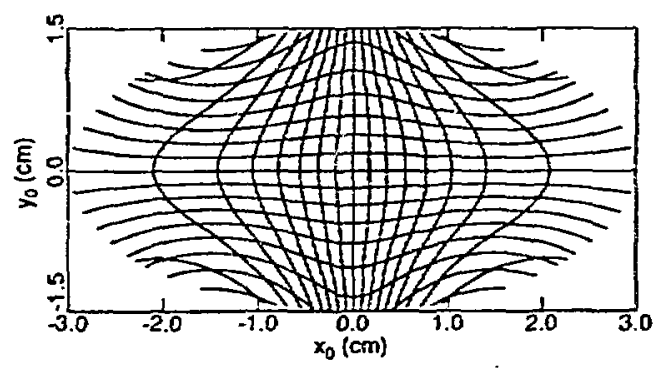

Fig. 4: The contour plotting for $X_{0}=\Delta_{x} / \Sigma$ and $Y_{0}=\Delta_{y} / \Sigma$ for the elliptic bcam chamber.
$1.32 \mathrm{~cm}$. However, this was shifted to $x_{p}=3.38 \mathrm{~cm}$ due to the mechanical constraint of the mounting flanges.

If the electrodes are not rectangular, $X_{0}$ and $Y_{0}$ are limedependent, and the result of measurement will depend on the timing of data acqusition. This error duc to the timing jitter will be larger for wide-band detection than for narrow-band detection at low frequency, say, a few hundred $\mathrm{MHz}$. The measurement error can be expressed as

$$
\delta x_{0}=-\frac{\delta S_{x}(l)}{S_{x}(t)} x_{0}
$$

$S_{\mathrm{X}}(1)$ is the sensitivily as a function of lime. Using hexagonal electrodes in place of circular ones to facilitatc analytic integration over the electrode surface, typical error is found to be less than $100 \mu \mathrm{m}$ per $1 \mathrm{~cm}$ of beam excursion from the beam chamber center. It is to be noted that it will diverge to infinity when $\Sigma$ crosses zero while $\Delta_{\mathrm{x}}$ does not. If the timing jitter is small (less than $10 \mathrm{ps)} \mathrm{or} \mathrm{if} \mathrm{a} \mathrm{narrow} \mathrm{band} \mathrm{deteclion}$ scheme at a few hundred $\mathrm{MHz}$ is used. this error will be reduced to a negligible level (less than $10 \mu \mathrm{m} / \mathrm{crn}$ ).

\section{CONCLUSION}

The characteristic of the BPM system for the APS sturage ring was studied analytically and numerically, and the results agree very well. This suggests that the presence of the photon beam BPM system. Using the analylical model, the oplimal position of the electrodes was determined such that the sensitivity is as close as possible in $\mathrm{x}$ and $\mathrm{y}$ directions taking into account other mechanical constraints. A possible source of error in the measurement of the beam position using nonrectangular electrodes was analyzed. The error was found to be typically of the order of $100 \mu \mathrm{m}$ per $1 \mathrm{~cm}$ of beam excursion from the center of the beam chamber and can be reduced significantly by employing proper timing schemes and signal processing.

\section{REFERENCES}

[1] T. Ring. "Beam Position Monitors for the High Brightness Lattice." Daresbury Laboratory Report, DL/SCI/TM41A. 1985

[2] J. Hinkson, J. Johnson, and I. Ko, "Advanced Light Source (ALS) Beam Position Monitor," Proceedings of 1989 IEEE Particle Accelerator Conference, 1507. 1989

[3] J.-C. Denard, A. Carniel, R. Aiello, and T. Monaci, "Beam Position Monitoring System for Elettra," Proceedings of 1990 European Paricle Accelerator Conference, 726. 1990

[4] J. H. Cupérus. "Monitoring of particle beams at high frequencies," Nucl. Instr. and Meth. 145, 219. 1977.

[5] J. Borer and C. Bovet, "Computer Resporise of Four Pick-up Butons in an Elliptical Vacuum Chamber," LEP Note 461, 1983, and references therein 